\title{
Comentarios
}

\section{Reflexiones ante el proceso político nacional}

El Salvador está en vísperas de un importante acontecimiento político: la celebración de las últimas elecciones presidenciales del siglo XX. El gobierno que gane las elecciones habrá de enfrentar ingentes desafíos en la lucha por el desarrollo económico y social, la disminución de la pobreza, el desempleo, la recuperación del agro y la integración centroamericana. En el plano social, el nuevo gobierno tendrá que resolver a corto plazo lacras como la inseguridad ciudadana, la violencia en sus más graves manifestaciones - homicidios, robos, violaciones, secuestros, etc. - y el deterioro ecológico creciente, que - como lo puso de manifiesto la reciente tragedia provocada por la depresión tropical "Mitch" - hace más vulnerables a los sectores más desprotegidos del país.

El aparato de gobierno es una instancia imprescindible para hacer frente a los problemas sociales y económicos más acuciantes para la mayor parte de la población. Para ello, su trabajo debe orientarse en una dirección distinta de la seguida en la última década del siglo XX: si el quehacer gubernamental de las dos administraciones de ARENA ha privilegiado los intereses de los sectores más ricos del país - en detrimento de los intereses de la mayor parte de salvadoreños-, un cambio de rumbo gubernamental debe hacerse cargo del bien común, pues, de lo contrario, seguirán prevaleciendo en el país las dinámicas de exclusión social y económica. Con un cambio de gobierno, una nueva oportunidad de orientar la marcha del país aparece en el horizonte; pero para que ese cambio de materialice va a ser necesario, más allá de las buenas intenciones, contar con los mejores talentos y capacidades del país. El nuevo gobierno, ¿va a estar dispuesto a apoyarse en esos talentos y capacidades, o va a continuar la vieja práctica de recurrir a los incondicionales del partido?

De las elecciones de marzo de 1999 saldrá electo un nuevo presidente de la república. No deja ser preocupante la posibilidad de que ARENA controle el ejecutivo en un tercer período, pues no sería extraño que las inercias del segundo mandato arenero pervivan en una tercera administración llevada adelante por el mismo partido. Una de las dinámicas que fortalece a la democracia es la alternabilidad en el poder; no experimentar esa dinámica puede tener efectos perniciosos sobre la marcha de la democratización en El Salvador. Como quiera que sea, independientemente de quien gane en marzo de 1999, debe haber un compromiso público por parte de la fuerza política ganadora de cambiar el rumbo seguido en los últimos diez años. De cara a la viabilidad del país, el cambio de rumbo, en lo económico, lo social y lo político, es un reto ineludible. Ojalá que así lo entienda el nuevo jefe del ejecutivo.

Ciertamente, hay males que acompañan al desempeño político en El Salvador, y que hay que tomar en cuenta para no hacerse falsas expectativas acerca de lo que se puede lograr en el futuro. En la coyuntura electoral, la reflexión sobre esos males se vuelve una necesidad imperiosa, pues desde ella se pueden anticipar situaciones más graves y también avizorar alternativas para hacerles frente. 


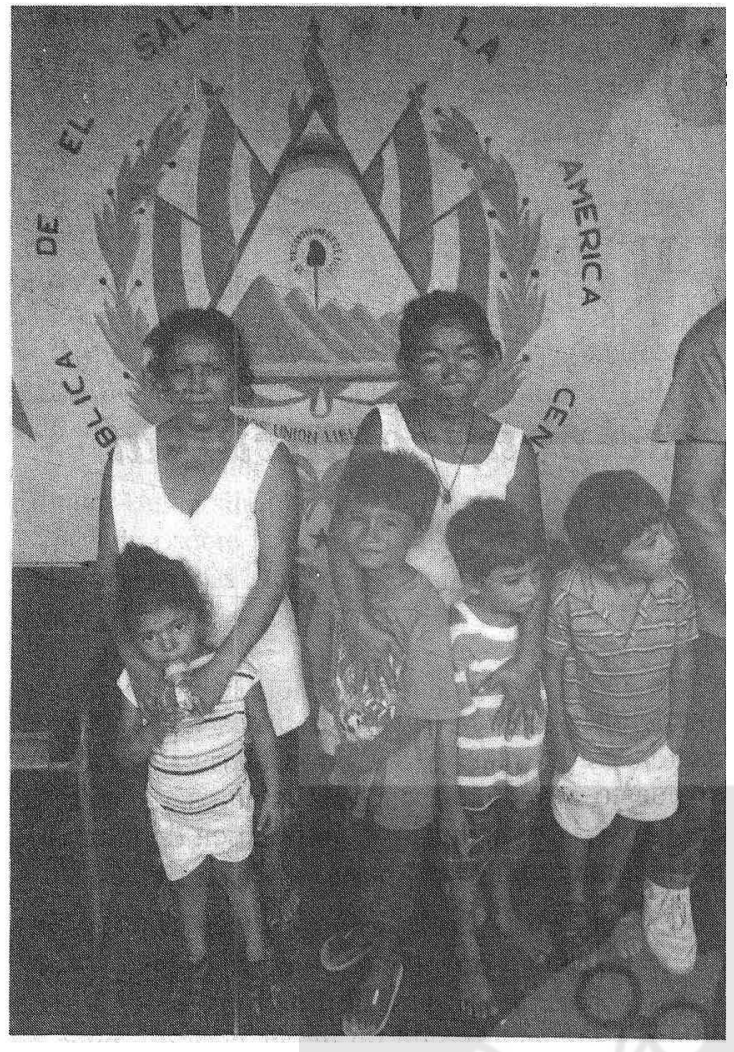

En la actualidad, a la práctica de los políticos salvadoreños se asocian características no precisamente honrosas. Entre las más preocupantes están las siguientes: $(a)$ corrupción y deshonestidad; $(b)$ incompetencia profesional, que muchas veces raya en la ignorancia más palmaria; $(c)$ predominio de los intereses particulares por sobre la búsqueda del bien común; $(d)$ elitismo antidemocrático, y $(e)$ existencia de una clase política resistente a la renovación interna.

Estos aspectos han contribuido al desprestigio de la política, pues los valores éticos más profundos de ella - búsqueda del bien común, honestidad pública y privada, apertura a las mejores soluciones para garantizar el imperio de la justicia - han sido dejados abiertamente de lado. En El Salvador, la política ha roto los vínculos con los criterios éticonormativos que son, precisamente, los que desde siempre han hecho de aquélla una actividad socialmente necesaria y prestigiosa.

Al romper con la ética, la política salvadoreña se ha convertido en lo que ahora es: una actividad de la cual, por sus incontables vicios y escasas virtudes, no cabe honrarse.

Quizás es la percepción social la que mejor expresa lo mal que andan la política y los políticos. Innumerables sondeos de opinión pública han puesto de manifiesto que importantes sectores de la sociedad no se sienten representados en los partidos políticos. Cosa grave, pues uno de los propósitos de las instituciones partidarias es representar -o por lo menos convencer de que representana determinados sectores sociales, lo cual habrá de traducirse en votos. La no representatividad se traduce en merma de votos para los partidos, es decir, en la práctica del abstencionismo, cuyo niveles pueden llegar a ser sumamente altos - por ejemplo en las elecciones de 1997 fue superior al 60 por ciento.

Paralelamente a la certeza de que los partidos no representan sus intereses, grupos sociales significativos manifiestan abiertamente su desconfianza en los partidos y sus líderes. No sólo no creen que aquéllos y éstos puedan hacer frente a los problemas del país, sino que también desconfían acerca de su buena voluntad para hacerlo.

Esta desconfianza tiene raíces en su desempeño efectivo, caracterizado por la incompetencia, componendas, el chantaje y los compra/venta de favores. Los partidos y sus líderes, entonces, tienen un doble problema: (a) un porcentaje elevado de la población no se siente representado por ellos, y (b) no cree que los partidos y sus líderes puedan (o quieran) resolver sus problemas. Incompetencia y mala voluntad, pues, se asocian en la opinión pública a los políticos. Estos no sólo no pueden hacer las cosas que son de su competencia, sino que no están interesados en involucrarse en tareas que no les reditúen algún beneficio personal.

El desempeño político ha tenido un importante efecto sobre el conjunto de la sociedad: ha fomentado la apatía, la desconfianza, el irrespeto a las leyes y la irresponsabilidad social. Desde el ejercicio político han proliferado valores contrarios al afianzamiento de la democracia y sus instituciones. De este modo, resabios de la cultura política autoritaria que prevaleció en el pasado reciente - caracterizada por el predominio del más fuerte, la discrecionalidad de los funcionarios públicos, las amenazas y el chantaje - han encontrado un clima propicio para reproducirse en El Salvador de la postguerra. 
Son los partidos políticos y sus líderes los principales responsables de ello, pues no han sabido, no han podido o no han querido volverse creíbles y confiables. Es como si los partidos y sus líderes estuvieran en contra de la participación crítica de los ciudadanos en los asuntos de interés nacional; es como si los partidos y sus líderes encontraran en la apatía ciudadana un resguardo para su mediocridad y deshonestidad.

Un aspecto relevante en la configuración de la actividad política son sus vínculos - turbios muchas veces- con el poder económico. Por lo general, un gobierno necesita de una relativa autonomía para ejercer correctamente su función de superación y síntesis de las inevitables visiones e intereses particulares. Esto no ha sido posible en El Salvador porque los políticos salvadoreños exponen abiertamente sus ambiciones económicas, se someten sin dignidad a las presiones de los poderosos — sin respeto para sí mismos o para sus representados-, reciben dádivas y halagos del poder económico y, con estas mismas motivaciones, disputan entre ellos por el control de los aparatos partidarios. Lo más grave, sin embargo, surge cuando se borra la distinción entre intereses políticos e intereses económicos o cuando, para asegurar estos últimos, se traiciona el mandato de los electores.
En El Salvador, las dos administraciones de ARENA han enturbiado esa distinción, la han borrado para su mayor conveniencia. Ambas administraciones fueron copadas por figuras empresariales, las cuales trabajaron tesoneramente para que las políticas económicas les fueran favorables a sus intereses particulares. Ello restó autonomía a la gestión gubernamental - sometida a las presiones que desde dentro han ejercido determinados grupos empresariales - e impidió a ambos gobiernos diseñar e implementar un plan de desarrollo nacional que en verdad fuese tal. La presencia de figuras empresariales en puestos claves del gobierno no ha sido, en el caso salvadoreño, algo beneficioso para el país en su conjunto, ya que estas figuras se han servido del aparato gubernamental para fortalecer la posición financiera de sus empresas, sin considerar las exigencias de un desarrollo equilibrado para el país.

En fin, en la actualidad, los políticos salvadoreños cargan con pesados lastres, de los cuales tienen que deshacerse si quieren convertirse en factores potenciadores de la democratización de El Salvador. No está claro cómo lo van a hacer; lo que sí está claro es que sin una drástica transformación en el ejercicio político, la desconfianza ciudadana hacia la política (y los políticos) continuará profundizándose.

\section{Luis Armando González}

